\title{
A study on the effect of telecom terminal customization service strategy on conversion tendency based on the system dynamics
}

\author{
Li Zhihong, Li Xueping, Shao Ming \\ School of Business Administration, South China University of Technology, Guangzhou, China
}

Email address:

bmzhhli@scut.edu.cn (Li Zhihong), lixueping2412@sina.com (Li Xueping)

\section{To cite this article:}

Li Zhihong, Li Xueping, Shao Ming. A Study on the Effect of Telecom Terminal Customization Service Strategy on Conversion Tendency Based on the System Dynamics. Science Innovation. Vol. 2, No. 3, 2014, pp. 27-36. doi: 10.11648/j.si.20140203.12

\begin{abstract}
Based on our previous research, this paper puts forward a comprehensive theoretical framework and establishes a system dynamics model of the effect of the telecom terminal customization service strategy (TTCSS) of on the users' conversion tendency and simulates it. The simulation results show that the model better reflects the reality of the effect of the telecom operators' terminal customization service strategies on the uses' conversion tendencies. The control analysis made from the simulation results has an important reference to the three operators to improve their terminal customization strategies.
\end{abstract}

Keywords: Telecom Operators, Terminal Customization Service Strategies, Users’ Conversion Tendencies, System Dynamics

\section{Research Background}

Professor Shu Huaying [1] thinks that the core function of the telecom operation is the production capacity of the network construction and maintenance, business and product management as well as the telecom customer management. And the business and product management function is the telecom networks to provide various business and product, including the basic business and value-added services. With the advent of the era of $3 \mathrm{G}$, the telecom business from the traditional voice, short message business develop for the rich, various types of high bit rate of the mobile data business. The traditional terminal is unable to meet the needs of data business due to the lack of communication between terminal manufacturers and operators and at the same time the terminal model independent development appeared many problems, so mobile operators for terminal customization become inevitable. Through customized terminals (CT), operators use the exclusiveness of network plus package way of bundling locking the user better in their own hands. It becomes a measure for operators in the early stage to attract users and later maintain high quality users, acting as an important factor that affects users' conversion tendency directly.
Currently, researches on operators' terminal customization strategies mainly focus on two aspects. One is from the perspective of users' needs to accurately grasp the factors which affect the users' needs. Buchanan [2] proposes the significance of the $\mathrm{CT}$ to the Internet from the perspective that users want to have more function; Wang Liang [3] believes the mobile terminal develops in the direction of function strengthen, multimode, customization and open platform to meet customers' needs under the changing market conditions and operators-driving; Zhang Jinli, etc. [4] draws that the function, quality and design of terminals, value-added service are the key factors affecting consumers' terminal choice, and put forward the corresponding strategies of terminal customization through the empirical investigation combined with the actual needs of the consumers; Wang Haolu [5] puts forward the pattern customers participating in the strategies and the overall customers' participation, telecom operators fully using of customers' ability by their participation to optimize product structure and improve the customer perceived value of the terminal product through introducing the theory of customers participation. Another is from the perspective of CT strategic choice. Operators and terminal manufacturers eventually form a stable cooperation mode after repeated game. Li Jianwei [6] analyzes and compares the mobile 
terminal strategies of the three operators in China, deeply analyzing their different cooperative strategies; Liu Guoliang [7], by repeated game, analyzes the bilateral moral hazard of operators in cooperation with terminal manufacturers in the process of development and marketing, establishing a solvable bilateral incentive model; Huang Yijun [9] comes to a conclusion that operators customizing within a certain ratio range of terminal customization product is good for the stability and development of the industrial chain using system dynamics to simulate different CT patterns. Research on telecom users' conversion tendency mainly involves the reasons and the motivation for transformation behavior. The reason why users convert operators are mainly related to satisfaction, trust, perceived value, perceived quality, word of mouth and replacement attraction [9-13] and the motivation includes competitors attracting, perceived value and conversion cost [14-16].

Based on the above research, researches on the terminal customization strategies are mostly by theoretical and qualitative ways to analyze the impact of terminal customization strategy on customers' demand and the relationship between suppliers and operators. While there is less empirical or simulation method and lacks systematic analysis method. For the conversion tendency, few researchers focus on the terminal customization service strategy which the three operators care most. From the perspective of system theory, the influence of terminal customization service strategy on users' conversion tendency is systemic, nonlinear and dynamic. It is a whole having a specific structure and function which is composed of several influence factors connected with the surrounding environment. Therefore, based on the theory of customer loyalty theory, perceived value, conversion cost theory and the theory of consumers' behavior, this paper uses the method of system dynamics to study the influence of terminal customization service strategy on users' conversion tendency for the purpose of obtaining a more comprehensive understanding.

\section{Construction of the System Dynamics Model}

The purpose of this paper is based on the applicability of using system dynamics method to study the impact of TTCSS on users' conversion tendency and though modeling, simulation of the transformation tendency to provide suggestions for operators to control users' conversion and maintain users, as well as to provide certain reference for the question of reservations of telecommunications industry in our country under the new environment.

\subsection{Applicability Analysis of System Dynamics}

System dynamics is a discipline to analyze and research information feedback system and also an integrated cross-discipline to understand and solve the problems of the system. It emphasizes the system behavior is mainly determined by the internal mechanism of the system and with the advantages and disadvantages of both quantitative and qualitative research. Through modeling and simulation, help people understand the structural reasons of the system dynamic behavior so as to analyze and design highly leveraged solutions to solve the problem of dynamic complex and improve the performance of the system [17-19].

The influence of the TTCSS on users' conversion tendency is systemic, nonlinear and dynamic. On the one hand, the system components are numerous and data deficiencies or relationship is difficult to quantify; on the other hand, the influence of the TTCSS on users' conversion tendency is with clear boundary and the impact process follows a certain pattern with frequent circulation and feedback. The structure of the model of system dynamics is based on the feedback loop, which in this case, the application of system dynamics modeling has a strong applicability and advantage.

\subsection{Definition of System Boundaries and Model Assumptions}

\subsubsection{Definition of System Boundaries and Theoretical Framework}

Accurately defining the system boundary is the key step to the success of the model. Defining the boundary of the system should focus on the core issue and factors without substantial function can be ruled out in the system, which is based on the purposes as well as the research object [20]. For this paper, the main variables is the telecom users' conversion tendency and the system elements are the factors of the impact of the TTCSS on users' conversion and the influence strength of measures the operator adopted to save. Under this strategy, factors affecting continuance or conversion including users' perceived value for operator, satisfaction, consumption habits and alternative attraction. Because the conversion tendency of this article is under the TTCSS, thus saving measures taken by the operators is only considered the relevant and terminal performance improvement measures and the marketing effects intensity of bundling strategies.

Based on above theory analysis and research on service conversion and combined with the impact of the TTCSS of Chinese major telecom operators on users, build the theoretical framework of the impact of the TTCSS on uses' conversion tendency (FIG. 2-1).

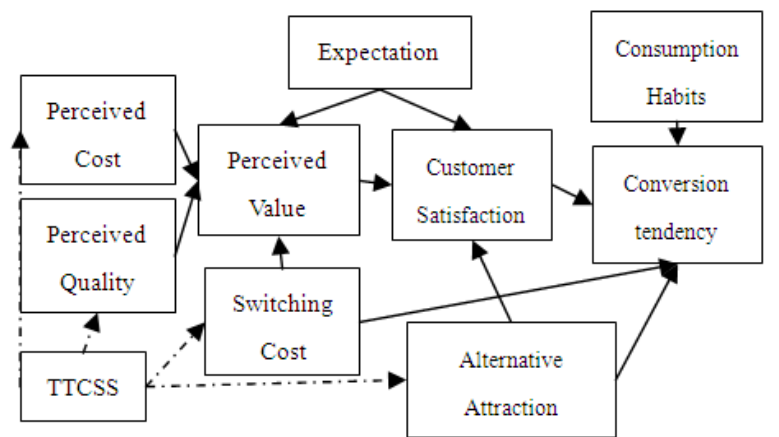

Figure 2-1. Theoretical Framework of the Impact of TTCSS on User' Conversion Tendency 


\subsubsection{Basic Assumptions of the Model}

The basic assumptions of the model is as followed:

(1) Assumes that within the system there are only two operators. Due to the needs of the modeling analysis, name one of the telecom operator as $\mathrm{S}$ operator $(\mathrm{S})$ and the other is the alternative (A). At the beginning of the simulation, $\mathrm{S}$ and $\mathrm{A}$ have the same performance of the customized terminal; (2) Because the technical level of each brand terminal manufacturers is difficult to measure, the level of the operators within the system is considered the highest; (3) According to the actual operation, operators detect the loss of users indirectly so can adopt right bundling strategy and strengthen the investment; (4) Without a detailed user segmentation, assume all the user's psychological characteristics, values and personality characteristics are same so there is a general model which is available for the simulation.

\subsection{Causal-Loop Diagram of the Impact of TTCSS on Users' Conversion Tendency}

In the model of this study, the major factors influencing the users' conversion tendency under the TTCSS mainly have two aspects: one is the customers' own perception and psychological factors, namely, customers' perceived value, satisfaction, switching costs, etc., which enhance the users' willingness to keep; One is the stimulation of external objective factors, mainly the alternative attraction, which improve the user's conversion strength. According to the above descriptions of the causal-loop diagram, we set up the causal-loop diagram of the impact of TTCSS on users' conversion tendency, as shown in figure 2-2:

As can be seen from the causal-loop diagram, the performance of the customized terminal equipment is affected by operator' input intensity. Apparently, the greater the intensity, the better the performance of the customized terminal, also the better experience of the users with the such aspects as function, service and so on of the terminal. But correspondingly, clients are denied the right to select service providers to some extent, which to a certain extent reduces the customer's satisfaction. As for the measures to develop the performance of the terminal, the current domestic operators are mainly on three aspects. One is to cooperate with the terminal brand manufacturers; one is the investment on the performance of the terminal itself; the last is customizing for built-in terminal services. Accordingly, if the operator has not made the corresponding input, as the technology innovation is bound to its custom terminal performance is reduced, and if made into its replacement, the replacement appeal will increase, thus stimulating the operator customers enhance the strength of its conversion operators intend to. In addition, in order to retain users and maintain relationship, during sales of customized terminals operators tend to bind some marketing strategies at the same time.

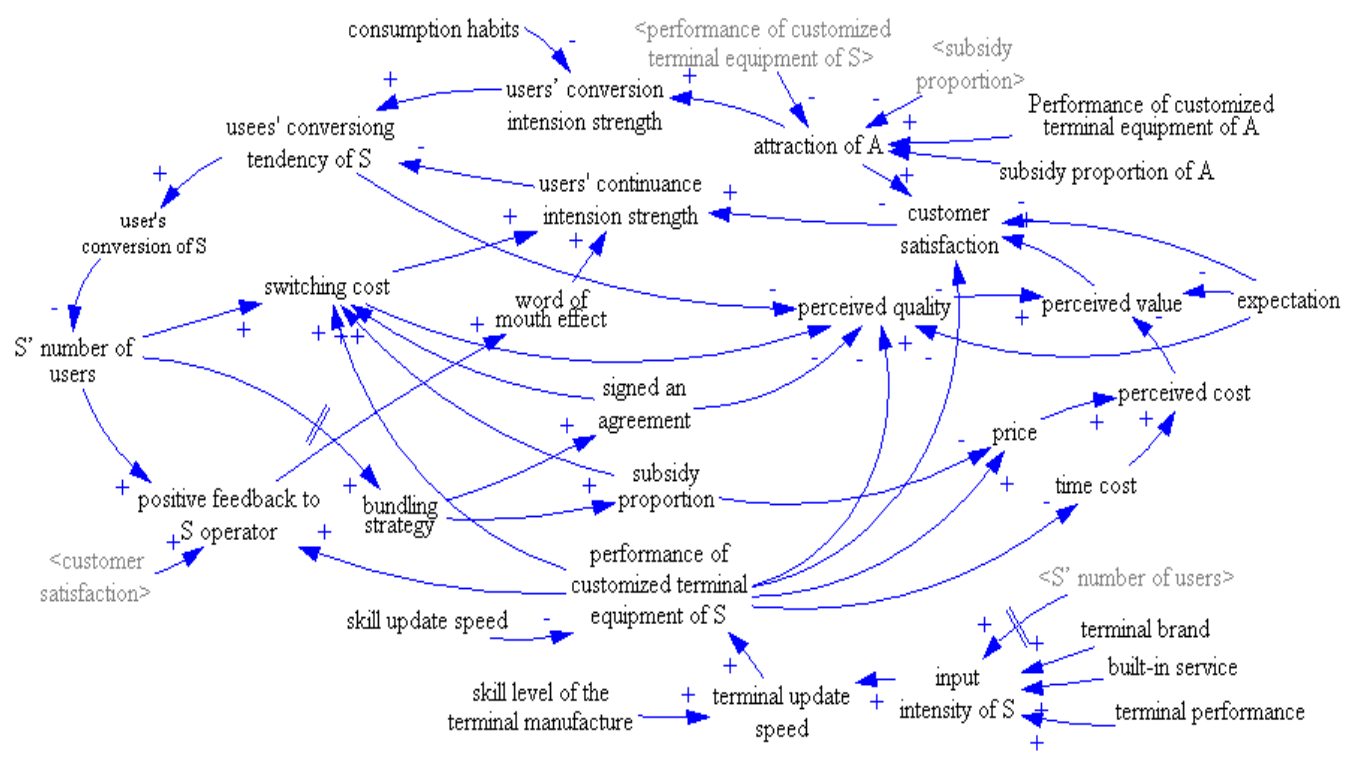

Figure 2-2. Causal-loop diagram of the impact of TTCSS on users' conversion tendency

The bundling strategies of domestic operators generally contains two main contents: one is the need to sign an using agreement with a certain time; one is to make subsidy policy, which is typically by operators through phone expenses to users in order to reduce users' perception of price when buying customized terminal. The return of money is not one-time but within a period of time, thus increasing the customized terminal customers' switching costs, thereby reducing users' service conversion tendency in order to reduce conversion.

\subsection{Flow Graph of the Impact of TTCSS on Users' Conversion Tendency}

Causal-loop diagram can vividly describe the relation and feedback process of the variables in the system, but it is only a qualitative description. The flow diagram can express the management and control of the system, so it is the perfection and supplement for the causal-loop diagram. According to the causal-loop diagram above, draw the flow graph of the impact of TTCSS on users' conversion tendency (FIG. 2-3). 


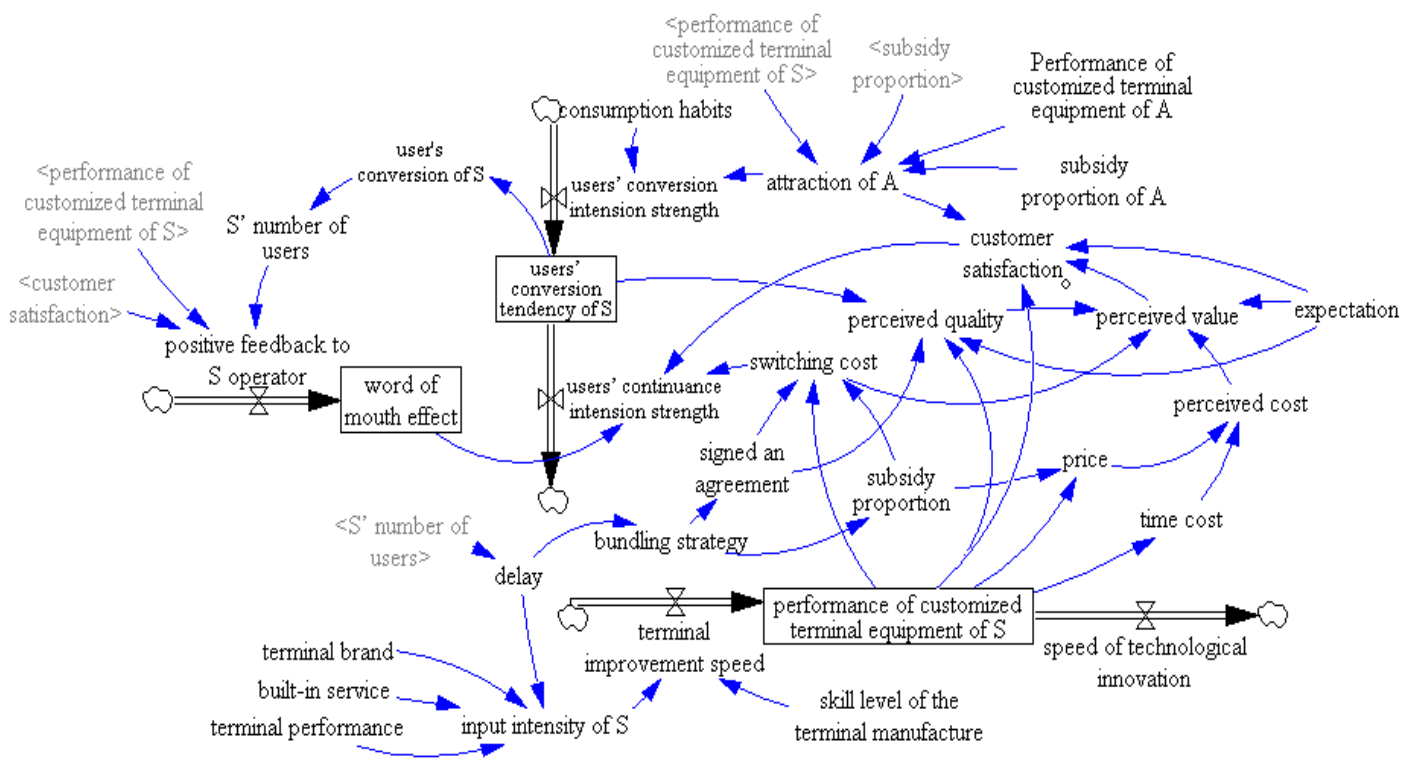

Figure 2-3. Flow graph of the impact of TTCSS on users' conversion tendency

The data for this paper is not only the results from the previous empirical studies, but also by investigating the historical data from the telecom industry and experts interviews to set the parameters of the variables in the model. The model equations and initial value are set as follows: (01) Subsidy proportion $=$ WITH LOOKUP (Bundling strategy, $([(0,0)-(10,10)],(0,0),(1,0.1),(2,0.3),(3,0.7))) ;(02)$ Positive feedback to $\mathrm{S}$ operator $=$ customer satisfaction $* \mathrm{~S}$, number of users $+0.01 *$ performance of customized terminal equipment of $S$; $(03)$ Perceived cost $=0.22 *$ price $+0.11 *$ time cost; (04) Perceived value $=$ IF THEN ELSE $\left(0.83^{*}\right.$ perceived quality $-0.23 *$ perceived cost $-0.08 *$ switching cost $-0.07 *$ expectation $>0,0.83 *$ perception of quality $-0.23 *$ perceived cost $-0.08^{*}$ switching cost $-0.07 *$ expectation, 0.1); (05) Perceived quality $=0.29 *$ performance of customized terminal equipment of S $-0.11^{*}$ sign an agreement $-0.07 *$ users' conversion tendency of $\mathrm{S}$ operator- $0.05 *$ expectation $+0.1 ; \quad(06)$ Speed of technological innovation $=0.05 ; \quad(07)$ Price $=0.14^{*}$ performance of customized terminal equipment of S $-0.22 *$ Subsidy proportion; (08) Word of mouth effect = INTEG (Positive feedback to $\mathrm{S}$ operator, 0.1); (09) Bundling strategy $=$ IF THEN ELSE (delay $>=1,0$, IF THEN ELSE (delay $>=0.9,1$, IF THEN ELSE (delay $>=0.7,2$, IF THEN ELSE (delay $>=0,3,3)$ ))); (10) Expectation $=0.2$; (11) Built-in service $=1$; (12) Signed an agreement $=$ WITH LOOKUP (Bundling strategy, $([(0,0)-(10,10)],(0,0),(1$, $0.1)$, (2, 0.3), (3, 0.7))); (13) Time cost $=0.1-0.08^{*}$ performance of customized terminal equipment of $\mathrm{S}$; (14) Consumption habits $=0.075$; (15) Subsidy proportion of $\mathrm{A}=0.3$; (16) Performance of customized terminal equipment of $\mathrm{A}=0.4$; (17) attraction of $\mathrm{A}=\mathrm{IF}$ THEN ELSE( (1.1* Performance of customized terminal equipment of $\mathrm{A}+$ Subsidy proportion of A $-1.1 *$ Performance of customized terminal equipment of $\mathrm{S}-\mathrm{Subsidy}$ proportion $)>=0.15,\left(1.1^{*}\right.$
Performance of customized terminal equipment of $\mathrm{A}+$ Subsidy proportion of A -1.1* Performance of customized terminal equipment of S - Subsidy proportion), 0.15); (18) delay =DELAY3(S' number of users, 2.5); (19) Switching cost $=0.03+0.41 *$ Signed an agreement $+0.37 *$ Subsidy proportion $+0.13 *$ Performance of customized terminal equipment of S; (20) Users' continuance intension strength $=0.02 *$ Word of mouth effect $+0.07 *$ Switching cost $+0.19 *$ customer satisfaction; (21) Customer satisfaction $=$ IF THEN ELSE $\left(0.71 *\right.$ Perceived value $-0.09^{*}$ expectation $-0.08^{*}$ Alternative attraction $-0.01 *$ Performance of customized terminal equipment of $\mathrm{S}>0.05,0.71 *$ Perceived value $-0.09 *$ expectation $-0.08 *$ Alternative attraction $-0.01 *$ Performance of customized terminal equipment of S , 0.05); (22) Users' conversion intension strength $=0.24 *$ Alternative attraction $-0.13 *$ consumption habits; (23) Terminal improvement speed $=$ skill level of the terminal manufacture * input intensity of S; (24) Terminal brand =1; (25) Terminal performance $=1$; (26) Skill level of the terminal manufacture $=0.5$; (27) Input intensity of $\mathrm{S}=\mathrm{IF}$ THEN ELSE (delay $>=0.95,0.08$, IF THEN ELSE (delay $>=0.85$, $0.11 *(0.35 *$ Terminal brand $+0.4 *$ terminal performance $+0.25^{*}$ Built-in service), IF THEN ELSE (delay $>=0$, $0.13 *(0.35 *$ Terminal brand $+0.4 *$ terminal performance $+0.25^{*}$ Built-in service), 0.15))); (28) S' number of users $=$ IF THEN ELSE (1- users' conversion tendency >0, 1- users' conversion tendency, 0); (29) Performance of customized terminal equipment of $\mathrm{S}=$ INTEG (Terminal improvement speed - speed of technological innovation, 0.4); (30) User's conversion of $\mathrm{S}=\mathrm{IF}$ THEN ELSE (users' conversion tendency of $\mathrm{S}>=0.05,0.95^{*}$ users' conversion tendency of $\mathrm{S}$, 0 ); (31) Users' conversion tendency of $S=$ INTEG (Users' conversion intension strength - uses' continuance intension strength $+0.01,0)$. 


\section{Model Simulation}

\subsection{Model Simulation and Results}

In this paper, the Vensim software is be used to simulate

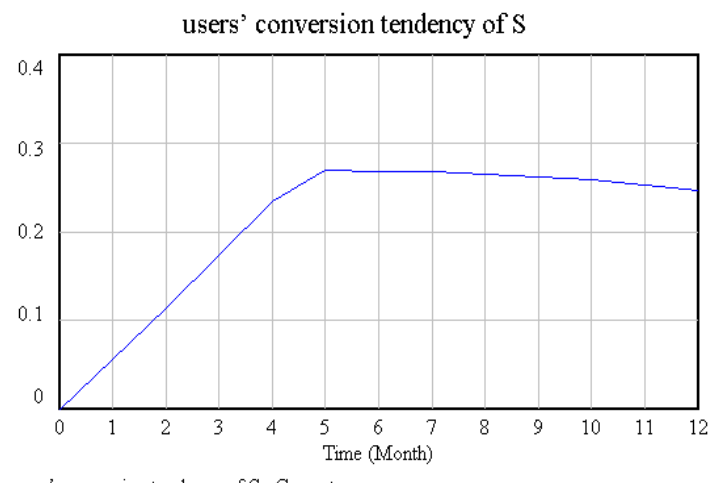

users' conversion tendency of $\mathrm{S}$ : Current

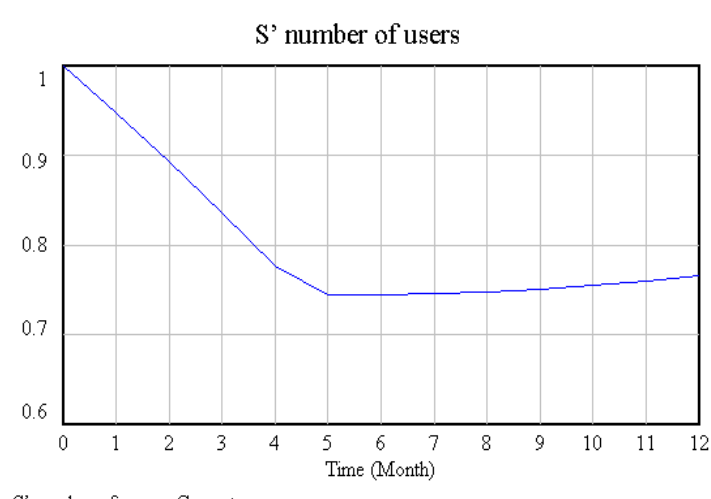

S' number of users : Current the model for 12 month life cycle of the impact of the telecommunications terminal customization service strategy on users' intention to convert. The simulation results are shown in Figure 3-1.

performance of customized terminal equipment of $\mathrm{S}$

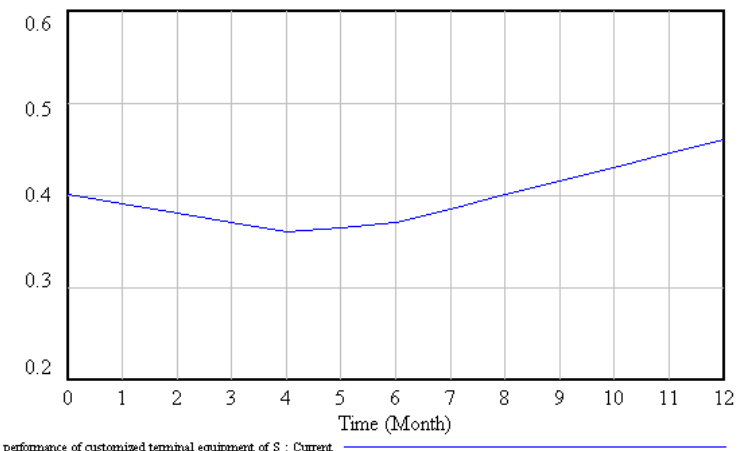

sers' conversion intension strength

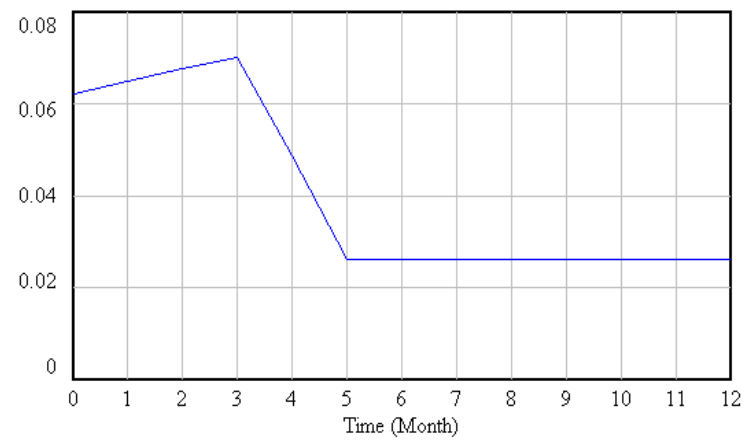

users' conversion intension strength : Current

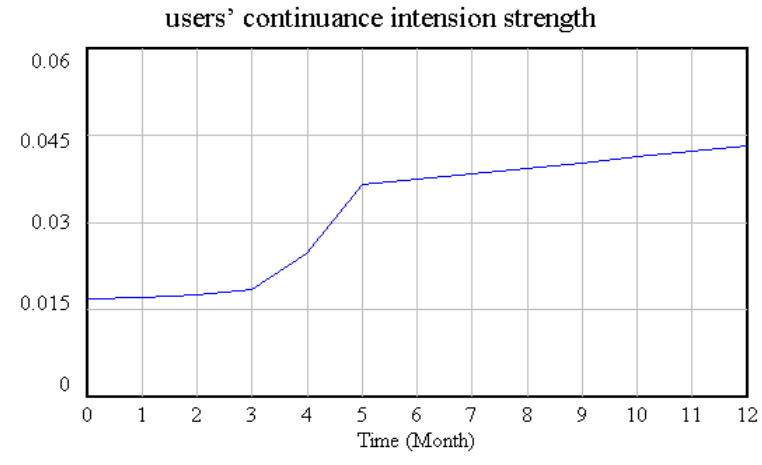

users' continuance intension strength : Current

Figure 3-1. The simulation results under the established parameters

According to the simulation results, the development trend of the variables can be divided into three stages. The first stage is the beginning of the simulation model to the third month. At this stage, because the enterprise does not take any action and pay no attention to the performance of the terminal equipment and the terminal technology updates and competitors change in marketing strategy as well as the user's own factor, users' continuance intention strength remained almost at the initial level and users' switching intention strength gradually increases and becomes higher than the continuance intention, ultimately resulting in the gradual rise of the users' conversion tendency, performance drop of the terminal equipment and the continual outflow of users. Beginning from the third month to sixth, the system enters the second stage. As company begins to take appropriate safeguard measures promoting the performance of the terminal equipment and changing marketing strategies, users' continuance strength begins to improve rapidly. On the contrary, users' switching Intention strength begins to decline. There reached a turning point around the fifth month, which means user's continuance intention strength begins to be stronger than switching intention strength. That 
is why there are turning points in the graph of users' conversion tendency, terminal equipment performance and the number of users. The last stage is from the sixth month to the end of the simulation. During this period, users' continuance intention strength still improves slowly and the switching intention reaches the lowest point and tends to balance. Strength of the two together have an impact on the tendency of users' conversion, and then the conversion tendency is under control and slows down along with the promotion of the continuance intention. At the same time, number of users increase and the performance of the customized terminal equipment have been significantly improved. This suggests that the conversion tendency is affected by the uses' continuance intention strength and the uses' switching intention strength, so operators can regulate these two factors to affect customer conversion tendencies. Meanwhile, the performance of the telecom customized terminal equipment increases in an opposite direction to the uses' conversion tendency, so operators should be able to improve the performance to adjust the customer's conversion tendencies.

\subsection{Control Analysis}

By the flow diagram and causal-loop diagram graph we know that among the factors to the user's continuance

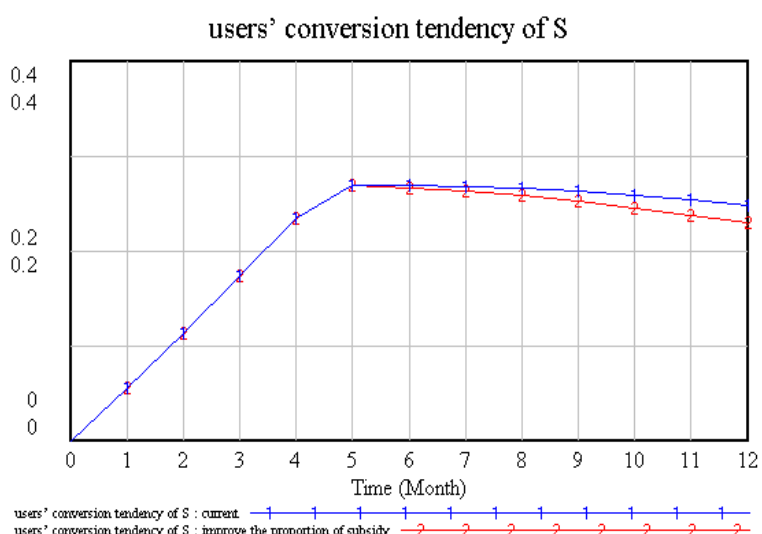

intention strength and switching strength, operators can control two main factors: one is the intensity of investment on the improvement of the terminal device performance; the other is the relevant bundling strategy the operators implementing. By changing the parameters, running and analyzing the simulation results under different conditions can analysis the corresponding control policy.

\subsubsection{Change Operator's Bundling Strategy}

The operators' bundling strategy of the customized terminal is mainly manifested in two aspects. One is to give certain subsidies in the form of telephones expenses to attract and maintain customer relationships; the other is by signing a contract for a certain period to maintain the customer for not switching to other networks.

1. Enhance the proportion of subsidies

According to the feedback of the number of users, the operator takes appropriate measures to adjust, thus the user's conversion tendencies began to fall in a better direction, but the speed is slow. Keeping other values unchanged, modify the table function by improving the proportion of subsidies from $(2,0.3)$ up to $(2,0.4)$, namely to increase the operator's subsidies. Upgraded model simulation result is shown in Figure 3-2.

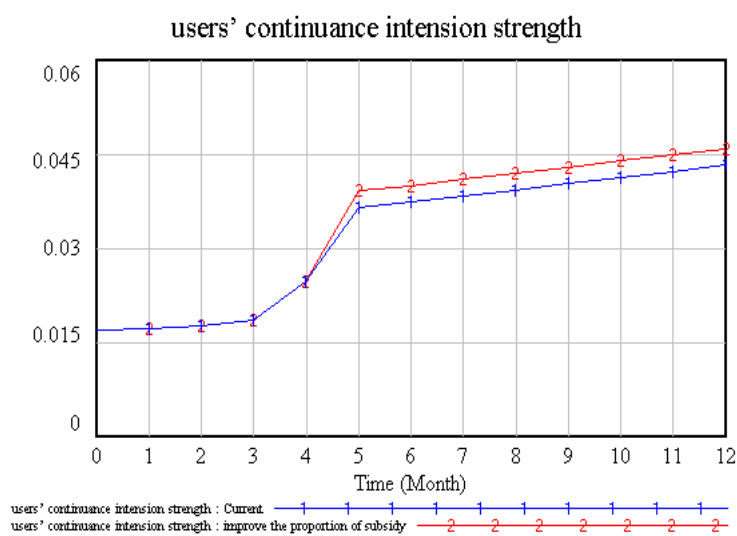

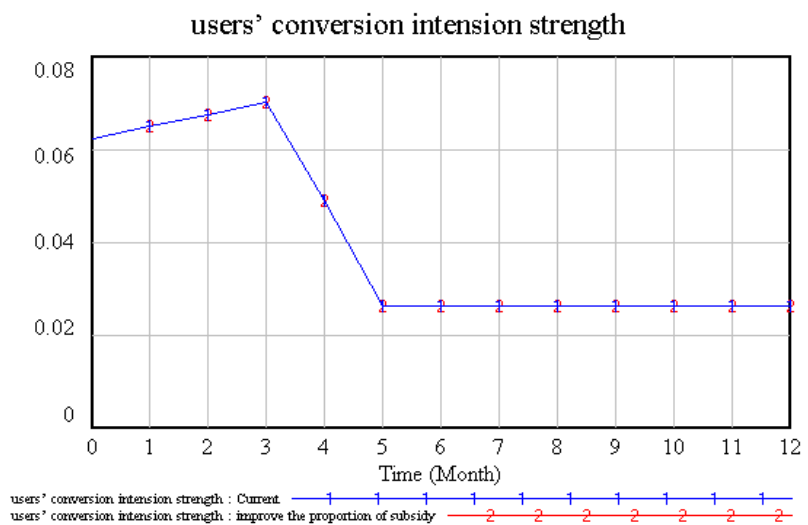

Figure 3-2. Simulation results of the proportion of subsidies enhanced

Enhancing the proportion of subsidies can significantly enhance the user's perception of switching costs and reduce the price perception; thereby further affects the users' continuance intension strength which has been significantly 
improved. As the proportion of subsidies and subsidies among operators has little difference and its impact on the attractiveness of alternative is small, so the impact of enhancing the proportion of subsidies on users' switching intention was not significant. But customers are also sensitive to telephone expenses and preferential policies according to its impact on uses' switching intention. Therefore, telecom operator can through increase the appropriate subsidies to increase the viscosity of the users to enhance their intensity to keep using, so as to better maintain customer relationships.

2. Extend term of the agreement

As before, with other parameters unchanged, modify the table function by extending the term of the agreement from $(2,0.3)$ up to $(2,0.4)$ and re-run the model. The comparisons of the simulation results between models adjusted before and after are shown in Figure 3 -3:
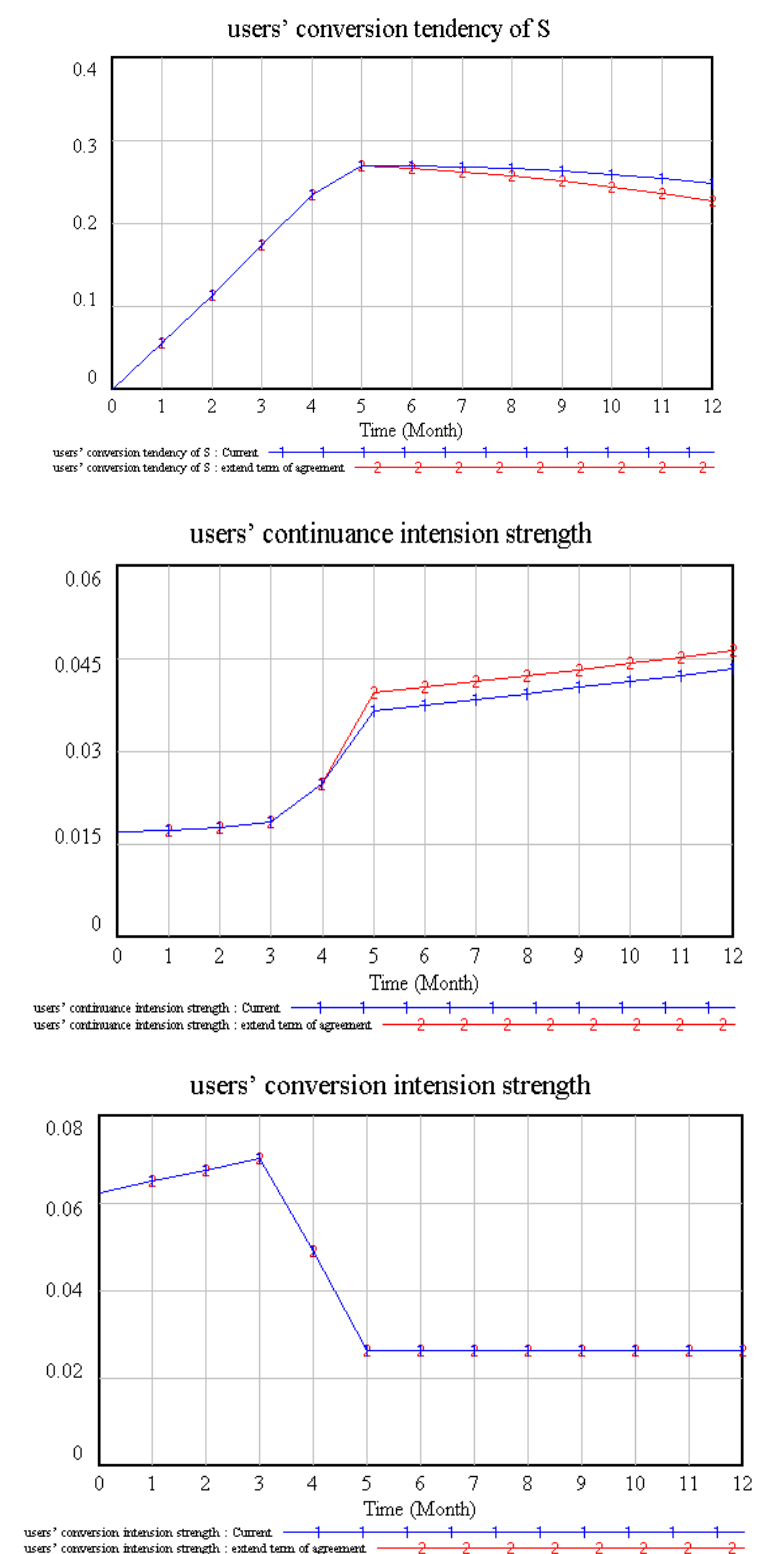

Figure 3-3. Simulation results of Extending term of the agreement
Extending term of the agreement plays a significant role for the rate of increase of the uses' continuance intention strength, but has no difference with before in the users' switching intention strength, which is because two auxiliary variables of uses' switching intention are not affected by signing an agreement, thereby extending term of the agreement has no effect on users' switching intention. Therefore, the impact on uses' switching intension is similar to the subsidies policies by enhancing users' continuance intension strength to control the conversion tendencies. However, by the observation of impact of signing an agreement on the causal-loop diagram graph, its impact on the perceived quality is negative and on the conversion cost positive, as shown in Figure 3-4. The longer the term of the agreement, the lower is the perceived quality, the higher the switching costs.

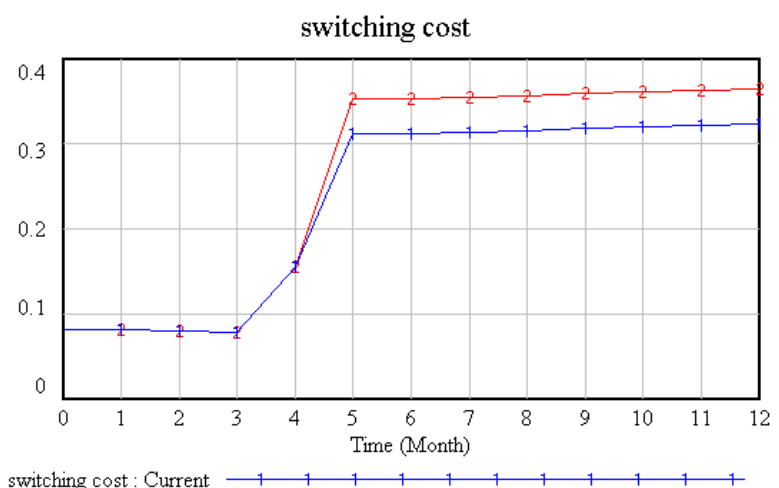
switching cost : extend term of agreement \begin{tabular}{lllllll}
\hline & 2 & 2 & 2 & 2 & 2 & 2
\end{tabular}

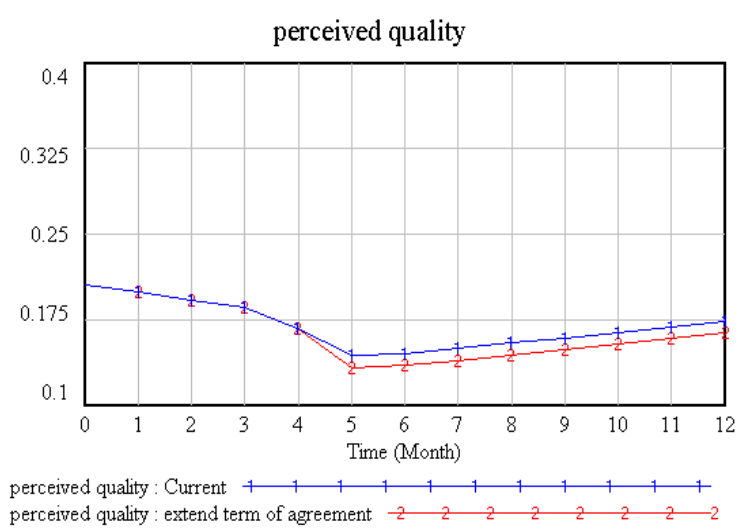

Figure 3-4. Impact of extending term of the agreement on the costs of conversion and perceived quality

Although appropriately extending the term of the agreement can indeed reach a certain role in customer retention, through a binding agreement is with a certain amount of mandatory which will reduce the user perceived quality of the operator. If this negative impact lasts long, it will have a negative impact on users' continuance intention for the lack of impact on the perception of cost when the term of the agreement ends. Therefore when operators make decisions in the length of the agreement term, they should take the negative impact on the perception of follow-up services because of long term of the agreement into account. 
They can find a length users generally accepted.

\subsubsection{Adjust the Investment in Improving the Customized Terminal Equipment}

From the front simulation results can be seen, the development trend of the conversion of customers and the performance of the terminal equipment is just the opposite. So by adjusting operators' intensity of investment can try to improve the performance of the terminal equipment, which is in order to enhance the performance of customized terminal equipment.

1. Increase the intensity of the comprehensive investment in Customized terminal equipment

In the model of the effect of the telecom terminal customization service strategy on the users' conversion tendency, the intensity of the investment in every aspect of the customized terminal equipment of the operator is set as 1 . Similar to the control simulation with the above process, keeping parameters in other equations constant, increase the intensity of the investment in the customized terminal equipment by $20 \%$, namely increase every aspect of terminal equipment investment levels to 1.2. Run the simulation model to obtain simulation results which is shown in Figure 3-5:
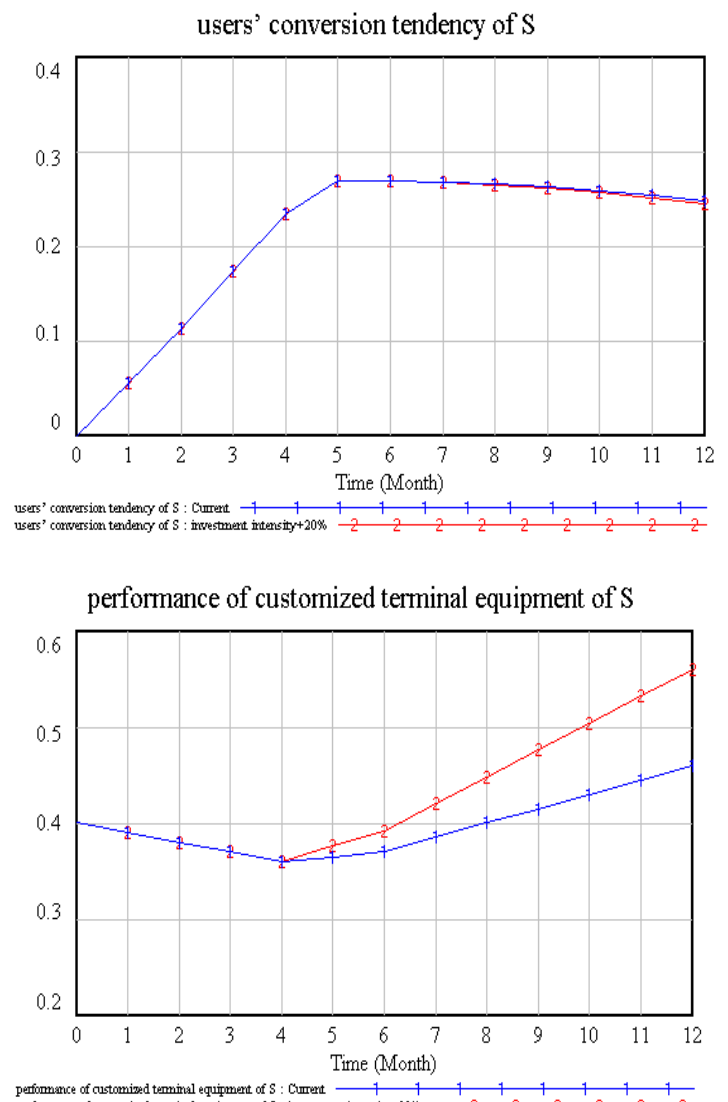

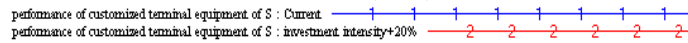

Figure 3-5. The simulation results of increasing the intensity of investment on the customized terminal equipment

As can be seen from Figure 3-5, the improvement rate of the performance of the customized terminal equipment is clearly much faster than the original when the operator increases the intensity of the comprehensive investment. With the improvement of the performance, users' conversion tendency has also been within a certain amount of control. Through analyzing the flow diagram and the causal-loop diagram graph can find out the performance of customized terminal equipment has a direct-acting on many elements, both positive and negative effects, which on the one hand by influencing alternative's attraction affects customers' switching intention strength, on the other they will have an impact on users' continuance intension strength. In addition, in the simulation period there were two inflection points in the trend of the performance of customized terminal equipment and users' conversion tendency. The first inflection point occurs at the same time and the second inflection point delays slightly in the simulation of the performance due to the information collection.

So by increasing the input into the improvements on customized terminal can enhance the performance of customized terminal equipment and also has a certain control action to the customers' conversion tendency. Therefore, operators can appropriately increase the investment intensity on customized terminal equipment to enhance the performance of customized terminal equipment as soon as possible to in order to control the conversion tendency of customers and to maintain good customer relations.

2. Adjust the investment proportion in various aspects of customized terminal equipment

Operators' investment in customized terminal equipment is mainly in three aspects: Terminal brands, terminal performance and built-in services. In the initial setting of the parameters of the model, the inputs on every aspect of the terminal device are the same with the investment ratio of $1: 1: 1$. But the impact of every aspect of the improvement of the customized terminal equipment on the overall performance of the terminal is not the same. Obviously the investment on the terminal performance improves the performance of the terminal equipment fastest. Thus, under the premise without changing other parameters and the intensity, adjust the original input ratio $1: 1: 1$ to $1: 3: 6$, namely built-in service $=0.3$, Terminal Brand $=0.9$, terminal performance $=1.8$. After running the model, the simulation results are shown in Figure 3-6:

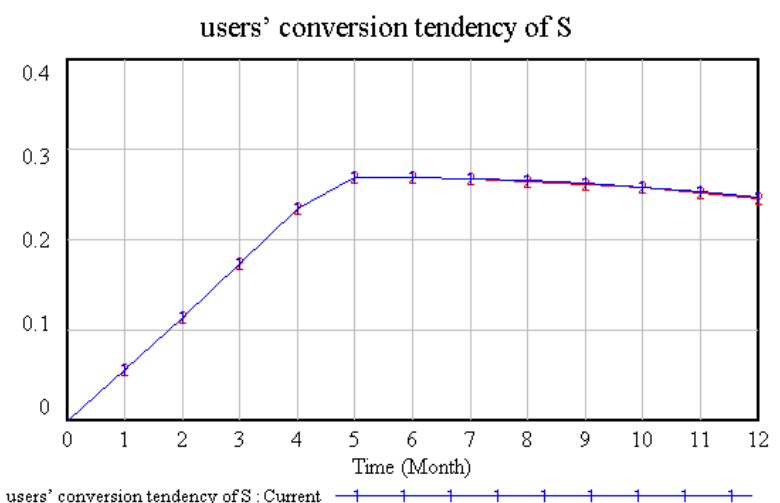

users' conversion tendency of S : adjust proportion $\begin{array}{llllllllllllll}2 & 2 & 2 & 2 & 2 & 2 & 2\end{array}$ 


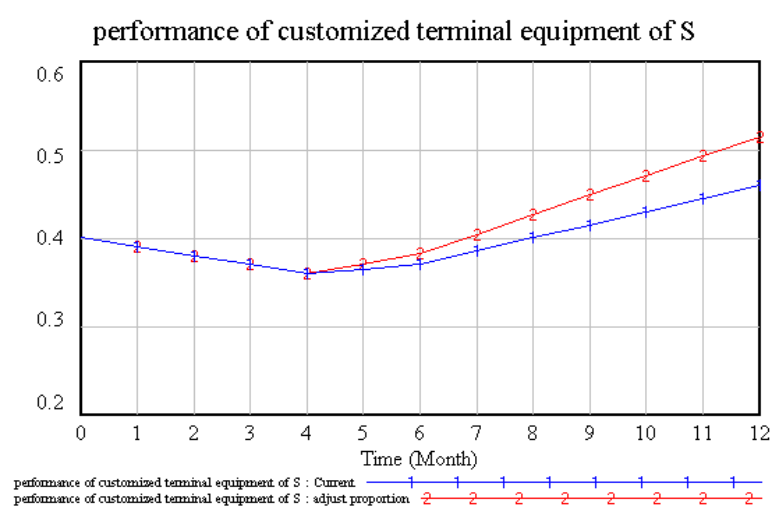

Figure 3-6. The simulation results of adjusting the input ratio from 1:1:1 to $1: 3: 6$

As can be seen from Figure 3-6, when the operator appropriately adjusts the inputs in all aspects of the customized terminal equipment, the improvement rate of the performance is clearly much faster than the original. With the improvement of the terminal equipment performance, users' conversion tendency gets some control. The analysis of the direct-acting role of the performance of the customized terminal equipment factors and the inflection point is the same as the former. So operators can adjust the investment proportion in all aspects of terminal equipment for custom terminal equipment to improve the performance of the customized terminal equipment as soon as possible to control customers' conversion tendency and to maintain good customer relations.

3. Compare the two Improved methods of input
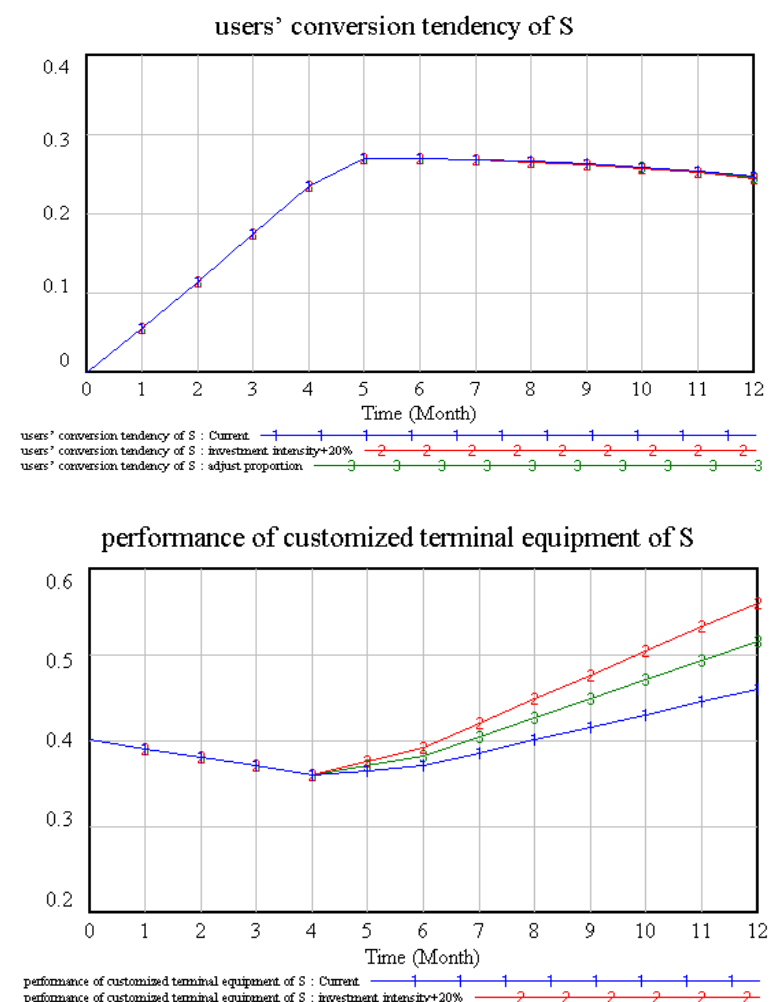

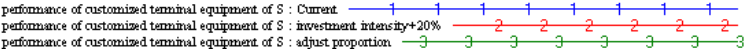

Figure 3-7. Impact of the two inputs ways on users' conversion tendency and the performance of terminal equipment
The former two ways are dedicated to improving the performance of the customized terminal equipment to influence and control customers' conversion tendencies. Here we will do a simple comparison with the two control results, the comparing results shown in Figure 3-7:

From the lifting speed of the terminal equipment of the two ways, the overall intensity of investment increased by $20 \%$ is better than adjusting the proportion to $1: 3: 6$ without changing the original input intensity. But for the effect of the users' conversion tendencies, the overall intensity of investment increased by $20 \%$ is a little better than adjusting the proportion to 1:3:6 without changing the original input intensity. That is, the effect of an overall increase by $20 \%$ input intensity is more apparent.

However, increasing the intensity of investment will increase the operator's investment and operation costs. From the viewpoint of cost savings, through proper adjustment of the terminal equipment investment can almost have the same effect and purpose by increasing the costs, but without increasing investment costs. Therefore, when invest to enhance the performance of the customized terminal equipment should seek to follow a scientific investment ratio under the same input intensity but not invest blindly relying on increasing input intensity.

\section{Conclusion}

The emergence of telecommunications customized terminal not only promote the healthy and rapid development of $3 \mathrm{G}$, but have chosen as a new marketing tools of operators to compete for and retain users, then how to develop customized strategies turns into a major concern of the three major terminal operators. This paper come to the conclusion that enhancing the proportion of subsidies and extending the term of the agreement in the bundling strategy, increase the intensity of customized terminal and adjusting the input ratio of every aspect can increase the magnitude of reducing of users' conversion tendency. The study has important reference to the three major operators to improve their terminal customization strategies: (1) the overall level of consumption of Chinese telecommunications market is not high, so consumers are more sensitive to price factors. When formulate the bundling strategies, can aim at customers' different consumption habits and consumption levels, using different subsidies. The form of subsidies can also be embedded in services the majority of consumers prefer or new services, thus improving user stickiness, control users' conversion tendencies. (2) Through market research, study the degree of influence of different terms of the agreement on customers' switching costs and perceived quality in order to find a reasonable period for the agreement to attract new customers and retain old customers. (3) by optimizing the proportion of investment in customized terminal to improve the performance of custom terminal equipment and control business costs, highlight the value of inputs, to maintain a competitive advantage of the customized terminal in the industry, so as to enhance the 
user satisfaction with the operator, reduce the attractiveness of substitutes, reduce users' conversion tendency and promote the ability to attract more users in the early stage and maintain the users during the service process.

\section{Acknowledgements}

This research is supported by Major Program of National Science Foundation of China (Project No. 71090403/ 71090400) and by Program for New Century Excellent Talents in University (NCET-11-0153).

\section{References}

[1] Shu Yinghua, 2008, "Management of telecom operations", Beijing University of Posts and Telecommunications Press.

[2] G. Buchanan, S. Farrant, M. Jones, 2001, "Improving Mobile Internet Usability", the 10th International Conference on World Wide Web, pp 673-680.

[3] Wang Liang, Zhang Yanbin, 2007, "Current Situation and Trends of Domestic Mobile Terminal Market", Telecommunications Technology, vol.10, pp 29-33.

[4] Zhang Jinli, Li Yiming, Li Xiaoning, 2009, "Customized Mobile Terminal Strategy”, C-Enterprise Management, vol.4, pp 82-83.

[5] Wang Haolu, 2011, “A Study on Mobile Device Strategy for China Telecom", Nanjing University of Posts and Telecommunications.

[6] Li Jianwei, Hei Qili, Guo Lifang, "Analysis of Existing Policies and Future Direction of Domestic Carriers for the Mobile Terminal", Mobile Communications, vol.19, pp 13-16.

[7] Liu Guoliang, Fan Yuncui, 2010, "Research on Double Incentive between Telecommunications Operators and Terminal Manufacturers Based on Cooperative R\&D and Popularization", Science \& Technology Progress and Policy, vol.2, No.27, pp 8-11.

[8] Huang Yijun, 2004, "Research of Telecom Terminal Customization Based on System Dynamics", Journal of North China Institute of Technology, vol.25, No.5, pp 382-385.
[9] Rob Mattison, 2005, "Telecoms churn management", Beijing: Posts\& Telecom Press.

[10] Jonathan Lee, Janghyuk Lee, Lawrence Feick, 2001, “The Impact of Switching Costs on the Customer Satisfaction-loyalty Link: Mobile Phone Service in France", Journal of Services Marketing, vol.1, No.15, pp 35-48.

[11] Yan Haoren, Jia Shenghua, 2004, "Empirical Research on Customer Loyalty Driving in Mobile Communications", Telecommunications Science, vol.5, pp 66-69.

[12] Li Zupeng, Zhang Wenhua, Zhang Fan, 2006, "Customers really lost?", C-Enterprise Management, vol.5, pp 32-34.

[13] Liu Yong, 2007, "Study on the Strategy of Recapturing Lost Customers in Chinese Telecom Industry", Huazhong University of Science and Technology.

[14] Yonggui Wang, Hing-Po Lo, 2002, "Service Quality, Customer Satisfaction and Behavior Intentions: Evidence from China's Telecommunication Industry", Info, vol.6, No.4, pp 50-60.

[15] Zhou Jun, 2009, "Mechanism of Motivation of Customer Switching Service Providers", Research on Financial and Economic Issues, vol.2, No.7, pp 37-42.

[16] Chen Kaibo, 2007, "A Research upon Customer Switching Antecedents and Mechanism in Mobile Communication Industry", Dalian University of Technology.

[17] Mohamed M. Naim, Denis R. Towill, 1994, "Establishing a Framework for Effective Materials Logistics Management", International Journal of Logistics Management, vol.5, No.1, pp 81-88.

[18] Benita M. Beamon, 1998, "Supply chain design and analysis:: Models and methods", International Journal of Production Economics, vol.55, No. 3, pp 281-294.

[19] Denis R. Towill, 1996, "Time compression and supply chain management - a guided tour", Supply Chain Management: An International Journal, vol.1, No. 1, pp 5-27.

[20] Zhong Yuanguang, Jia Xiaojing, Li Xu, 2009, System Dynamics, Beijing: Science Press. 